REVIEW ARTICLE

\title{
Idiopathic Parkinson's disease: Revised Concepts of Cognitive and Affective Status
}

\author{
Ann E. Taylor, J.A. Saint-Cyr and A.E. Lang
}

\begin{abstract}
Assumptions regarding increased risk of dementia in Parkinson's disease and of depression mimicking the endogenous form are reviewed and challenged from the perspectives of recent findings in both the neuropsychological and anatomical domains. Evidence suggests that depression, while frequent, behaviourally resembles the reactive variety and that selective impairment of cognitive functions considered to depend upon the integrity of the frontal lobes accompanies this disorder. In this regard, it is speculated that the cognitive alterations seen in non-demented parkinson patients are the consequences of dysfunction of the caudate nucleus which contributes significantly to the normal activities processed through the frontostriate "complex loop".
\end{abstract}

RÉSUMÉ: La maladie de parkinson idiopathique: revue des concepts sur l'état cognitif et affectif Nous revoyons les hypothèses concernant le risque accru de démence dans la maladie de parkinson et de dépression imitant la forme endogène et nous les mettons en doute dans le contexte des observations récentes dans les domaines de la neuropsychologie et de l'anatomie. Ces observations suggèrent que la dépression, bien que fréquente, ressemble au point de vue du comportement à une dépression réactionnelle et qu'une atteinte sélective des fonctions cognitives qu'on considère comme dépendente de l'intégrité des lobes frontaux accompagne cette affection. A cet égard, nous émettons la théorie que less altérations cognitives observées chez les parkinsoniens qui ne sont pas déments sont la conséguence d'une dysfonction du noyau caudé qui contribue de façon significative aux activités normales acheminees à travers la «boucle complexe» frontostriée.

Can. J. Neurol. Sci. 1988; 15:106-113

The majority of recent review articles concerned with the prevalence of dementia in Parkinson's disease (PD), the presence of specific intellectual deficits, and the incidence of depression, while acknowledging wide variability in results, implicitly and often explicitly support the assumption that significant mood and mental sequellae accompany this disorder..$^{1-4}$ However, in the course of a long-term neuropsychological assessment of idiopathic PD in over 200 patients the present authors have been impressed with the preservation rather than the loss of intellectual and emotional function in the majority of individuals. As this experience appears to contradict current wisdom a number of previous studies were re-examined from the perspectives of methodology, results, and conclusions, and compared to our findings. Some consistency but much divergence emerged. In an attempt to rationalize these differences our findings and those of several other recent neuropsychological experiments are presented followed by a brief review of what has been learned concerning the organic correlates of behavioural change. The review concludes with discussion of functional/ anatomical mechanisms within the basal ganglia which provide a framework for research at this centre.

\section{DEPRESSION}

According to a recent comprehensive review, estimates of the frequency of depression in PD, over the past two decades, have ranged from 30-90 percent. ${ }^{1}$ Clearly, despite discrepancies in patient selection, inconsistent definitions of depression, and differing methods of assessment, a considerable risk of this complication appears to accompany PD. Some investigators, aware of the association between neurotransmitter abnormalities and the endogenous form of depressive illness, ${ }^{5,6}$ argue for an intrinsic depression-linked process in PD based on known dysfunction in several monoaminergic systems. ${ }^{7-9}$ Others consider depressive affect to be a natural emotional reaction to inevitable progressive motor disability. ${ }^{10}$ In an attempt to clarify this issue, one recent study compared PD and arthritic patients on a standardized depression scale. Both groups suffer progressive physical disability but the latter does not involve

From the Playfair Neuroscience Unit, Departments of Anatomy and Psychology (Dr. Saint-Cyr) and Medicine (Dr. Lang). University of Toronto; Department of Psychology (Drs. Taylor and Saint-Cyr) and Department of Medicine (Dr. Lang), Division of Neurology, Toronto Western Hospital, Toronto

Received September 25, 1987. Accepted in final form January 26, 1988

Reprint requests to: Dr. A.E. Taylor, Department of Psychology, Toronto Western Hospital, 399 Bathurst Street, Toronto, Ontario, Canada M5T 2S8 
monoamine dysfunction. No quantitative or qualitative differences in level or nature of depression emerged, ${ }^{1}$ failing to support a disease-specific role for depression in the PD group.

We assessed the incidence of depression in PD by administering a standard screening test to all patients seen within a three month period. Seventy percent scored above the test cutoff point, indicating considerable mood disturbance in this group. ${ }^{12}$ However, the value of this approach in studying emotional issues in PD is questionable as even the most widely used depression scales contain no control for the effects of progressive motor disability. It is impossible to determine whether endorsement of many scale items reflects affective status or problems secondary to primary symptoms. Moreover, test cutoff points tell little of the nature or impact of affective dysfunction on behaviour.

Impact was indirectly assessed by comparing non-depressed PD patients to depressed PD patients on measures of shortterm memory, the mental function most severely altered in the endogenous form of depressive illness. ${ }^{13.14}$ No differences between the depressed and non-depressed PD patients emerged on any test of short-term memory administered. ${ }^{12}$ The performance of both groups remained within the normal range in contrast to a matched group of endogenously depressed patients who were severely impaired on three of the five measures used. These results suggested that, while $\mathrm{PD}$ patients frequently report depressive symptoms, nevertheless they do not resemble the subtype of depression associated with transmitter abnormalities, at least with respect to alterations in the most vulnerable of cognitive functions.

Organic Correlates Do "favourable" comparisons with arthritic and endogenously depressed patients imply that, despite a marked and understandable depressive reaction to their disease, physiological factors are not associated with PD patients so affected? A direct test of the relationship between serotonin levels and depression was recently conducted in a group of $P D$ patients. Although serotonin was reduced to a greater extent in the depressed group, no clear relationships between percentage decrease, depression, duration, or severity of disease were established. Some non-depressed patients suffered reductions equal to the depressed. ${ }^{15}$

Santamaria and his colleagues ${ }^{16}$ have recently proposed that PD patients with depression may represent a subgroup in whom occult disturbance of monaminergic function first presents as depressive illness. In a study of newly diagnosed PD patients depression was more frequent than expected and affected younger, less disabled individuals. These authors speculate that transmitter abnormalities in the depressed (latent) PD patients unmasked the neurological condition at an earlier stage. To date no epidemiological data are available to support this suggestion.

With regard to dopamine, the transmitter most affected in PD, destruction of the A10 dopaminergic cells in the ventral tegmental area (VTA) in rats is variously associated with hyperexcitability or hypomobility depending on the location and extent of lesion. In reviewing these experiments, Fibiger et $\mathrm{al}^{17}$ now speculate that this mesolimbic dopamine system is important in the anticipatory/motivational component of arousal. In this regard, Rogers et al, ${ }^{18}$ observing comparable bradyphrenia (mental slowing), in PD and depressed patients on a reaction time measure, suggest that cerebral mechanisms, responsible for speed of thinking and mood, may be affected in both disor- ders and involve the mesolimbic dopamine projection pathways, at least in PD.

However, in PD, loss of VTA cells appears relatively minor. ${ }^{19}$ Clinically, patients at this and other centres, ${ }^{20}$ unlike endogenously depressed individuals, maintain adequate social skills and are effortful in response to external demands. However, they demonstrate little spontaneous initiative. Together, these observations suggest that reactive mechanisms may be augmented by transmitter abnormalities which contribute to deregulation of arousal and mood control.

Admittedly, no consistent or reliable mood-related response to levodopa or dopamine agonists has been reported for the PD population. To date the underlying mechanisms in PDrelated mood changes remain far from understood, however, the behavioural assessment of depression in biochemicallycharacterized patient populations should help clarify clinical and etiological differences assumed under this general term.

In summary, while a high incidence of depression is consistently observed in PD, there is, as yet, no established association with transmitter abnormalities, nor is there evidence of depression-induced alteration in cognitive function.

\section{DEMENTIA}

"Global" Dementia: is generalized dementia a common feature of PD?

Epidemiological Studies Large sample surveys have consistently suggested that approximately $1 / 3$ of the PD population will become "demented" at some point in the disease. ${ }^{21.23}$ In re-examining these studies, Brown and Marsden ${ }^{24}$ have identified a number of critical methodological weaknesses which singly or in combination potentially inflated results. Absence of, or inconsistencies in the definition of dementia; variable sampling of the etiological mixture of parkinsonism; and failure to control for the toxic effects of anti-parkinson medication and/or depression were among the most serious design flaws cited. After careful recalculation these authors concluded that, in the idiopathic group, only $15 \%$ of the PD population is at risk for generalized cognitive decline. This figure correponds exactly with the incidence determined by a recent prospective study of severely disabled elderly PD patients using DSM-III criteria of dementia. ${ }^{25}$ It is important to note that such recent converging estimates of $15 \%$ with respect to PD do not differ significantly from a well established base rate of $10 \%$ in community-based individuals of 65 years or older. ${ }^{26}$

PsychometricStudies Several frequently quoted neuropsychological studies of the past 20 years have reported extensive generalized decline in the cognitive function of PD patients. ${ }^{27-30}$ Unfortunately, this approach is also fraught with methodological problems, for example: no control group despite the use of non-standard psychometric tests, ${ }^{27}$ inappropriate control subjects, ${ }^{30}$ a high incidence of patients with uni- or bilateral thalamotomy,,$^{29}$ or reliance on tasks with strong demands on motor speed, a factor which, a priori, places movement disordered patients in an unfavourable position. ${ }^{28}$ If these methodologically-flawed investigations are eliminated, no consistent reliable evidence of extensive generalized cognitive deterioration has yet been demonstrated in the neuropsychological study of PD.

We estimated the incidence of global dementia by submitting the first 100 consecutive idiopathic PD patients referred to a 
newly opened Movement Disorders Unit to an extensive battery of neuropsychological tests. Although this sampling strategy was specifically adopted to avoid bias in patient selection, it is possible that more motorically disabled patients received early admission on the basis of need. Despite this, the breakdown with respect to severity was entirely comparable to that reported in other definitive studies. ${ }^{31}$ The test battery was comprehensive, presence of generalized dementia strictly defined in quantifiable and easily replicable psychometric terms which conformed to DSM-III criteria. A frequency of $8 \%$ emerged rising to $12 \%$ if only those patients 65 years or older were considered. ${ }^{32}$ Seven additional patients displayed evidence of mental confusion (suspected to be related to pharmacotherapy affecting the dopaminergic system). Two others, with obvious disturbance to memory function, improved significantly following withdrawal of anticholinergic agents. None of the latter 9 patients had fulfilled all criteria for dementia and were therefore not included in the demented group.

When combined, results of critical retrospective analysis, ${ }^{24}$ recent prospective, ${ }^{25}$ and cross-sectional studies, ${ }^{32}$ strongly suggest that the former assumption that 1 of every 3 PD patients will sooner or later succumb to an irreversible demented state must be seriously questioned.

Organic Correlates With respect to possible etiological mechanisms underlying the dementia of $\mathrm{PD}$, early investigations reported a significantly higher degree of Alzheimer disease (AD) stig. mata in the brains of demented PD patients than in non-demented patients or age-matched controls. ${ }^{33-35}$ However, the implication that the majority of demented PD patients suffer from concommitant AD has not found universal support. It is clear that the association between PD-dementia and AD-related changes such as senile plaques (SP) and neurofibillary tangles (NFT) varies widely.

In AD, NFT and SP are prominent in the nucleus basalis of Meynert (nBM), hippocampus, amygdala, and temporal lobes. Severe reductions in cortical acetylcholine levels accompany these changes. ${ }^{36}$ In PD, significant loss of cells in $\mathrm{nBM}$ is typically accompanied by Lewy body inclusions ${ }^{36}$ and can occur without evidence of widespread AD-related NFT, SP, cortical atrophy, ${ }^{37.38}$ or dementia. ${ }^{39}$ Conversely, cortical Lewy Body disease is associated with dementia. ${ }^{40}$ Moreover, cell loss in locus coeruleus often uniquely accompanies PD. Its relationship to dementia is unclear. ${ }^{36-39}$ In fact, differentiable pathophysiological changes in AD and PD may well result in differentiable mental changes not readily combined under the rubric of dementia with its accompanying implication of generalized cognitive deterioration.

In the neurochemical domain, the complexity of biochemical abnormalities resulting from mid-and forebrain cell destruction in PD is only beginning to be appreciated ${ }^{41-43}$ while the role of putative neurotransmitters such as peptides and other substances which have been identified in the striatum remains unknown. Dementia may also be associated with peptide abnormalities at a cortical level, as, for example, decreased concentrations of somatostatin in frontal and entorhinal areas. ${ }^{44}$

It is possible that, when present, dementia in PD may be etiologically heterogeneous differing considerably from dementia in AD. In PD, global dementia is associated with variable neuronal loss involving one or several transmitter systems in the presence or absence of additional AD pathology (i.e. SP and NFT). Table 1 summarizes current knowledge of the pathologi- cal and biochemical disturbances in $\mathrm{PD}$, the various brain regions implicated, and the cognitive status of the patients sampled. As can be seen, extensive nigrostriatal DA deficiency occurs without global dementia although the possible cognitive sequellae of this change (see below) probably contribute to generalized intellectual compromise in those who develop dementia. As mentioned above, mesocortical DA deficiency is considerably less than nigrostriatal and can also occur in the absence of dementia. It can even be seen that severe loss of LC neurons accompanied by significantly reduced NA need not affect mentation, while the degree of $\mathrm{nBM}$ deterioration is not predictive of either Ach reduction in frontal cortex or mental status. Conflicting data such as these support the need for further clinicopathological studies to distinguish possible subgroups of patients with global cognitive decline resulting from specific pathological and biochemical changes.

\section{Selective Cognitive Changes}

If the majority of PD patients remain non-demented, is it possible to identify a specific cluster of cognitive impairments associated with this disorder?

Memory, visuospatial abilities, and executive functions have received special attention by neuropsychologists interested in this question. Broadly, such studies can be divided into clinical or experimental efforts depending on the attention paid to crucial methodological issues such as patient selection and choice of behavioural paridigms. In general, the more carefully designed experimental studies have traditionally been limited to non-demented patients and carefully constructed laboratory tests while clinical studies, typically concerned with general statements about, e.g. intelligence, memory, or visuospatial function, have treated the Parkinson population as if it were homogeneous. Moreover, the clinical approach renders the analysis of subroutines underlying performance difficult as the tasks employed were originally designed to differentiate braindamaged from normal subjects and require the simultaneous or interactive operation of various mental functions. For these reasons recent findings from the more reliable, more easily replicated experimental studies, will be briefly reviewed and compared to our own experience where applicable.

Memory Three frequently quoted experimental studies spanning the last 2 decades ${ }^{45-47}$ have suggested impairment in the ability of PD patients to freely recall verbal information. In the first, ${ }^{45}$ a deficit in the immediate recall of logical prose passages was observed. No delayed recall period was included in the experimental design. Both immediate and delayed recall were examined in our centre with the same tests. While patients exhibited a comparable mild deficit in immediate memory, no impairment was observed during later retrieval of information from long-term storage. ${ }^{48}$ This latter finding suggested that, although parkinsonians may initially encode information adequately, organization and consolidation of input require time to activate normal search strategies in memory. The demonstration of intact retrieval from long-term storage in our patients contradicted the second study ${ }^{46}$ where an undocumented weakness in memory consolidation was proposed. The third study, ${ }^{47}$ adopting classical cognitive tests of information processing, did suggest some impairment in the ability of PD patients to utilize semantic cues under conditions of supraspan learning, a finding replicated at our centre.

In terms of recognition memory, a less effort-demanding 
Table 1: Location of Neuropathology and Transmitter Systems in PD in Relation to Target Structures Associated with Cognitive Function

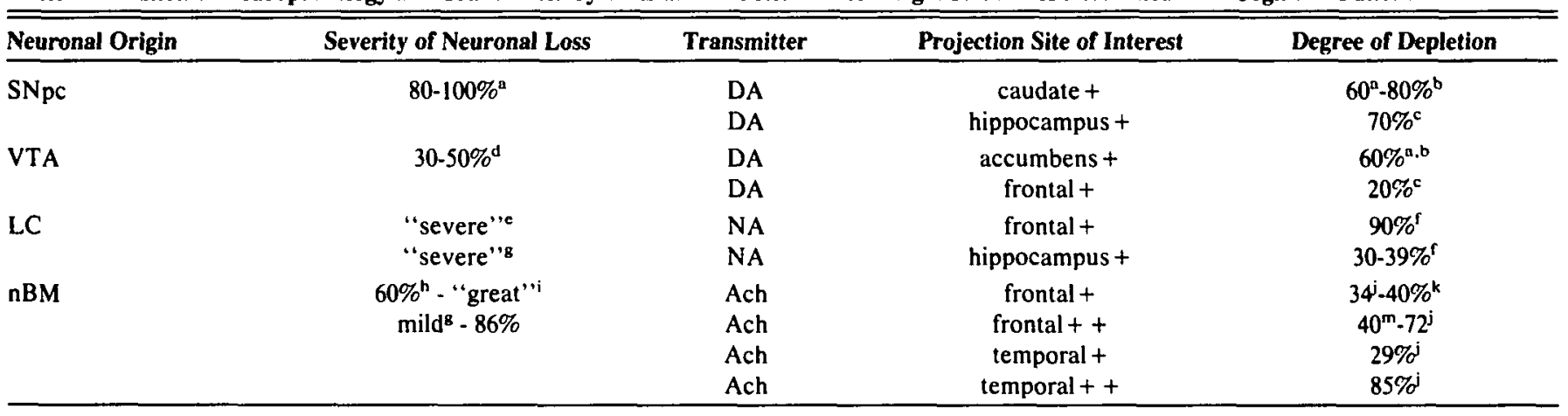

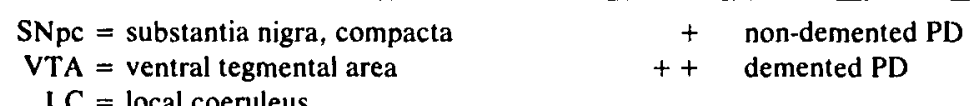

$\mathrm{LC}=$ local coeruleus

$\mathrm{nBM}=$ nucleus basalis of Meynert

$\mathrm{DA}=$ dopamine $\quad \mathrm{NA}=$ noradrenaline $\quad$ Ach $=$ acetylcholine

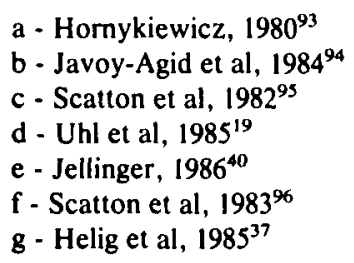

mental operation than free recall, a recent and extensive examination of the quantitative and qualitative performance of PD patients compared to well matched control subjects revealed no differences in cognitive processing. ${ }^{49}$ Our results are consistent with these findings. ${ }^{48}$

In summary, PD patients appear adequate on many memory task, particularly if sufficient time for consolidation is provided.

Visuospatial Abilities Since Proctor et $a^{50}$ first demonstrated a PD-related deficit in aligning extra- and intra-personal spatial co-ordinates under conditions of body tilt, reports of visuospatial impairment in PD have become increasingly frequent. In a recent study, visuospatial impairment was even attributed to Parkinson patients despite their adequacy on the most complex of such items administered. ${ }^{51}$ Interestingly, although Bowen (formerly Proctor) followed up the issue of more purely visuospatial dysfunction under normal postural conditions, and demonstrated difficulties in route planning and certain right-left decisions, ${ }^{52}$ she later reversed opinion regarding the importance of the visuospatial contribution. Subsequent testing led to the conclusion that problems with short-term memory and mental flexibility accounted for the earlier findings. ${ }^{53}$

Where former results have been challenged, one study involving a PD-related impairment in duplicating geometric patterns with blocks ${ }^{54}$ did not withstand replication. ${ }^{55}$ In a second case, simplification of arm movements on an experimental paradigm requiring the continuous tracing of an intermittently presented pattern ${ }^{56}$ did not confirm the earlier reported effect. ${ }^{57}$

Two very recent and well-designed experimental investigations failed to reveal any differences in patients and control subjects. ${ }^{58.59}$ Measures of simple and complex directional predictions and right-left manipulations allowed direct inspection of visuospatial processes. These results are consistent with our own where abilities examined included figure-ground discriminations, mental rotation and matching of abstract visual patterns, reasoning about numerical relations in space, delayed recognition of spatial position and designs, and right-left orientation. No deficits emerged with the exception of an isolated impairment on delayed recognition of spatial position. ${ }^{48}$ This unique deficit suggested dysfunction in a specific mnestic subroutine in visuospatial processing, i.e. a possible PD-related weakness in ordered spatial recall. As a selective weakness in the processing of ordered, verbally mediated information was also observed in our patients ${ }^{12}$ a non-modality-linked deficit in the serial tracking of events in short-term memory may be the "true" common mental operation responsible.

Executive Functions Tests falling into this category are the most cognitively demanding in terms of planning skills as they depend on transforming previously neutral stimuli into taskspecific associations to solve novel problems. Such tests are not uniquely linked to any sensory modality and do not utilize information stored within the familiar knowledge base. The planning necessary to succeed in such non-routine activities must be spontaneously developed by the subject, via the constant generation and switching of heuristic strategies.

PD patients have consistently demonstrated impairment on an "executive" test of card sorting (Wisconsin Card Sort) which depends on the ability to discover a correct sorting concept and then to shift this without warning to formulate a new successful strategy. ${ }^{45,60}$ A comparable cognitive deficit emerged in our studies. ${ }^{48}$ In motor executive planning tests our patients displayed marked difficulty executing a novel non speed-dependent task involving simultaneous performance of 2 simple but competing manual activities. These results replicated those of an earlier study. ${ }^{61}$ With respect to other planning deficits, failure to learn supraspan word lists over repeated exposure can be considered an executive weakness since success demands considerable subject-directed planning in organizing unrelated material. ${ }^{62}$ It could also be argued that the 
earlier failure of our patients to recall spatial order involved a planning deficit as some subject-directed method of identifying each new physically identical item must be employed.

Interestingly, in our extensive sampling of executive abilities, several tasks reputed to be highly demanding in terms of planning were undisturbed. ${ }^{48}$ Analysis suggested that these tasks provided an opportunity to resort to the stored lexicon of general information facts or to rely on explicit rules or visual cues. Equivalent compensatory guidelines were not available on tasks where deficits emerged.

\section{Summary of Specific Cognitive Deficits}

In general, there is now good evidence to suggest that any task which depends on pure visuospatial processing, time to consolidate organized information to-be-remembered, or recourse to externalized rules and/or the stored knowledge base is adequately performed by PD patients. Only non-routine situations, for which there is no prior training and/or no explicit guidelines appear reliably impaired. Our findings demonstrated that this planing deficit applied to verbal, visual, and sensorimotor tasks alike suggesting a specific PD-related impairment in the development of an "internal" (i.e. subject-directed) model of behaviour to guide action. Our understanding of this cognitive difficulty is reminiscent of Marsden's ${ }^{20}$ hypothesis regarding PD-related motor deficits in which the basal ganglia are considered responsible for the automatic execution of learned motor plans. If "internalized" (i.e. learned, non-visually guided) motor plans are not easily formed or updated in PD, then patients are forced to rely on external cues to guide movement. The strong reliance of basal ganglia disordered patients on external cues is present in $\mathrm{HD}$ as well where, for example, visually-primed recognition memory remains near normal despite severely impaired free recall in supraspan learning. ${ }^{63}$

Organic Correlates With respect to cognitive events, the relationship between altered physiological function within the caudate nucleus and specific PD cognitive deficits becomes important. It is now established that the neostriatum is extensively and selectively connected to the frontal cortical area through at least two $0^{64}$ or possibly as many as five $e^{65}$ partially closed parallel and segregated feedback loops carrying primarily motor (via the putamen) or cognitive (mainly via the caudate nucleus) information. While the entire cortical mantle, and especially "association areas", projects to the neostriatum, ${ }^{66,67}$ putaminofugal outflow, principally via the globus pallidus, and caudatofugal outflow, mainly via the substantia nigra pars reticulata, ${ }^{68}$ are preferentially relayed by thalamic nuclei to the supplementary motor area and prefrontal-premotor regions respectively. ${ }^{69-71}$ Major motor and cognitive divisions of the frontostriate system are illustrated in Figure 1 where, although the caudate is depicted as the main neostriatal component of cognitive processing, it is understood that the caudal-ventral portion of the putamen is also in receipt of temporal cortical input. $^{72}$

Anatomical organization implies that the consequences of basal ganglia dysfunction should find expression in abilities dependent upon the function of the cortical targets of striatal outflow. Such a model accurately accounts for motor dysfunction as: 1) pronounced somatosensory deficits are not associated with PD despite input from this cortical area to the putamen ${ }^{73}$ and, 2) surgical lesions aimed at the thalamic level of outflow are known to abolish tremor. ${ }^{74}$ With respect to cognitive processes, whereas behaviours sensitive to the integrity of the prefrontal and premotor cortical regions would be at risk, abilities thought to depend primarily on post-rolandic structures would not be directly implicated despite their considerable projections to the striatum.

The results of well-designed and replicated neuropsychological experiments are consistent with these principles of anatomical organization. Deficits in subject-organized planning have been attributed to pathology within the dorsolateral pre-frontal cortical area. ${ }^{75-78}$ In PD where dysfunction, not structural damage, characterizes the nature of frontostriate relations, the behavioural consequences would be considerably less than the impact of lesions at either level.

\section{Brain/Behavioural Relationships}

The demonstration of a PD-related selective impairment on tasks which require the development of an internally, subjectdirected plan of action provokes speculation concerning the role of the caudate nucleus in such behaviours. Numerous experiments in primates involving ablation of the orbitofrontal and dorsolateral subregions of the prefrontal cortex and their respective caudate projection sites have consistently produced similar behavioural deficits. ${ }^{79-80}$ This raises the question of whether caudate damage is responsible for such deficits because of its reliance on cortical input or whether, once damaged, it is able to disrupt behaviour through influencing cortical activity via the specificity of the "complex" feedback loop.

More sensitive techniques, analyzing the behaviour of single neurons during the performance of frontal-lobe sensitive tests in intact primates, have revealed important differences at the two levels. Cortical unit activity occurs with exquisite selectivity at all stages of behavioural testing i.e. at cue presentation, during delay periods, response, and outcome. ${ }^{81-83}$ In the caudate nucleus most neuronal activity is confined to the initial step of cue presentation and occurs only in relation to stimuli with task-specific meaning. ${ }^{84} \mathrm{~A}$ few neurons with similar properties have been observed in the putamen, ${ }^{85}$ while others have been detected in the nigral ( $\mathrm{SNr}$ ) region, the principal target of caudate projections. ${ }^{86}$ These data suggest that the caudate, remote from sensory input, may play a "priming" role in alerting the frontal cortex concerning the significance of the event to come. Where learning of novel cognitive routines requires time and practice to mature, such "priming" would allow the cortical component to concentrate on problem solving. In the absence of "priming", the significance of stimuli would require constant re-affirmation at the cortical level making progress slow and inefficient. Research with subhuman primates suggests that the neostriatum may be important for the slow establishment of cognitive "habits". ${ }^{87}$ If so, this hypothesis would be consistent with our findings in PD patients and with the proposed outflow model.

The importance of physiological integrity within the caudate nucleus to cognitive function is supported in normal elderly subjects where administration of $\mathrm{L}$-dopa resulted in significant improvement in effortful mental tasks such as word list learning. ${ }^{88}$ The question then arises as to why L-dopa treatment, which can result in dramatic alleviation of motor symptoms, does not reverse the documented cognitive deficits in $\mathrm{PD}$. Indeed, even marked fluctuations in motor symptoms which have been linked to treatment, are uncorrelated with cognitive status. ${ }^{89}$ There must therefore be a fundamental difference between the motor 
and complex loops with regard to the pathophysiology of PD and the action of dopamine in the SNpc and/or neostriatum. Other factors which might contribute to this paradox are: a) the relative restriction of dopamine loss within the caudate,,$^{90}$ and b) the differential sensitivity of motor versus mental deficit detection. It is noteworthy that motor symptoms announce themselves while cognitive symptoms must be uncovered through sophisticated probing. On the other hand, and of equal relevance, we observed that failure to respond to dopamine therapy was associated with greater loss of planning ability on tests sensitive to frontal lobe integrity. ${ }^{91}$ These patients are being followed to investigate any increased risk of future dementia.

We are also engaged in extended examination of the mechanism of cognitive "habit formation" with special reference to early PD where pathology is mainly confined to the basal ganglia. Recent results comparing the performance of PD and amnestic patients on single trial tests of declarative recall versus procedural memory tasks (where considerable practice in problem

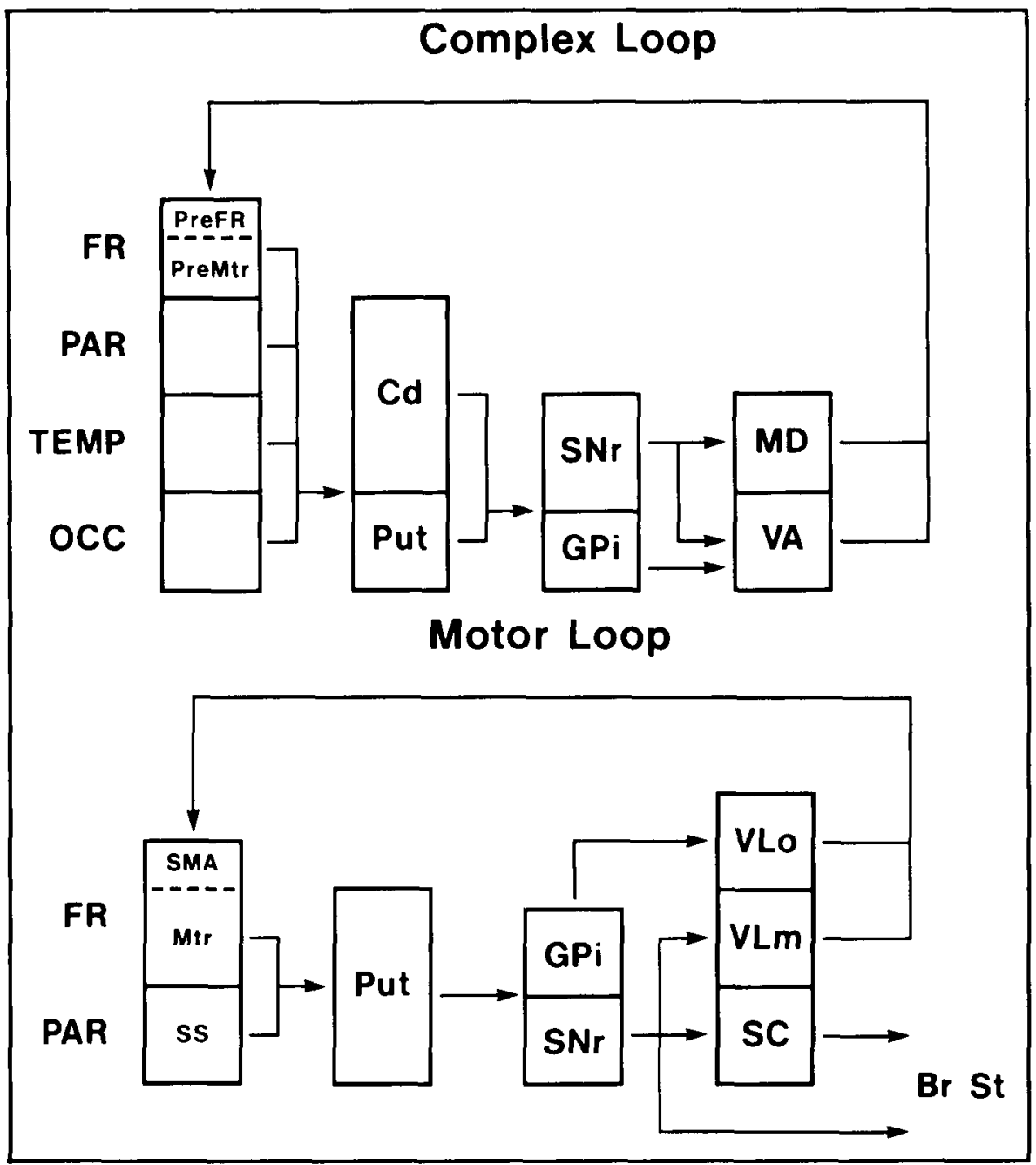

Figure 1 - Schematic diagram of the basic organization of the complex and motor loops. It is notable that cortical input to the complex loop originates from all cortical lobes and especially from the association areas, yet the circuit focusses its output onto the prefrontal and premotor cortical areas. For the motor loop, only motor and somatosensory areas feed into the putamen and the outflow is divided between brain stem centres mainly involved in ocular and neck motor control and the SMA. Only a small portion of the putamen and GPi are involved in the complex loop. Topographic details of the projections to specific subdivisions of GPi, SNr, MD and VA have been omitted for the sake of simplicity but can be found in references 65 and 68 . Similarly, details with regard to the organization of the cortico-striatal and thalamo-cortical projections are given in references 66, 67, 69-72.

$\begin{array}{llll}B r S t & \text { brain stem } & S C & \text { superior colliculus } \\ C d & \text { caudate nucleus } & \text { SMA } & \text { supplementary motor cortical area } \\ F R & \text { frontal lobe } & \text { SNr } & \text { substantia nigra, pars reticulata } \\ \text { gPi } & \text { global pallidus, pars internus } & S S & \text { primary somatosensory cortical area } \\ M D & \text { nucleus medialis dorsalis thalami } & T E M P & \text { temporal lobe } \\ \text { Mtr } & \text { primary motor cortical area } & V A & \text { nucleus ventralis anterior thalami } \\ \text { OCC } & \text { occipital lobe } & V L m & \text { nucleus ventralis lateralis thalami, } \\ \text { PAR } & \text { parietal lobe } & & \text { pars medialis } \\ \text { PreFR } & \text { prefrontal cortical areas } & V L o & \text { nucleus ventralis lateralis thalami, } \\ \text { PreMtr } & \text { premotor cortical areas } & & \text { pars oralis } \\ \text { Put } & \text { putamen } & & \end{array}$


solving is required) revealed a double dissociation in these two patient groups, ${ }^{92}$ supporting the hypothesis that the neostriatum is critical to the slow development of cognitively based routines.

Continued examination of cognitive subroutines in complex domains such as memory in PD and other neurological groups will help further define the forms of impairment in selective populations. Most importantly, the identification of remaining cognitive strengths, where they exist, is crucial to management and should not be obscured by uncritical assumptions. The casual conferring of a diagnosis of "dementia" or "depression" has great potential for impeding both current treatment and future research.

\section{ACKNOWLEDGEMENTS}

This work was supported by a Grant from The Canadian Parkinson's Disease Foundation.

\section{REFERENCES}

1. Mayeux R. Depression and dementia in Parkinson's disease. In: Marsden CD and Fahn S, eds. Movement Disorders. Butterworth Scientific, London: Neurology 1982; 2: 75-95.

2. Boller F. Mental status of patients with Parkinson's disease. J Clin Neuropsychol 1980; 2: 157-172.

3. Mindham RHS, Amed SWA, Clough CG. A controlled study of dementia in Parkinson's disease. J Neurol Neurosurg Psychiatry 1982; 45: 969-974.

4. Mortimer JA, Christensen KJ, Webster DD. Parkinsonian dementia. In: Fredericks JA, ed. Handbook of Clinical Neurology, Neurobehavioural Disorders. Elsevier Science Publications 1985; 2(46): $371-384$.

5. Garver DL, Davis JM. Biogenic amine hypothesis of affective disorders. Life Sciences 1979; 24: 383-394.

6. Schildkraut JJ. Neuropharmacology of the affective disorders. Ann Rev Pharmacol 1973; 13: 427-454.

7. Robins AH. Depression in patients with parkinsonism. Br J Psychiatry 1976; 128: 141-145.

8. Hoehn M, Crowley TJ, Rutledge CO. Dopamine correlates of neurological and psychological status in untreated parkinsonism. J Neurol Neurosurg Psychiatry 1976; 39: 941-951.

9. Horn S. Some psychological factors in parkinsonism. J Neurol Neurosurg Psychiatry 1974; 37: 27-31.

10. Mindham RHS, Marsden CD, Parkes JO. Psychiatric symptoms during L-dopa therapy for Parkinson's disease and their relationship to physical disability. Psychol Med 1976; 6: 23-33.

11. Gotham AM, Brown RG, Marsden CD. Depression in Parkinson's disease: a quantitative and qualitative analysis. J Neurol Neurosurg Psychiatry 1986; 49: 381-389.

12. Taylor AE, Saint-Cyr JA, Lang AE, et al. Depression in Parkinson's disease: a critical re-evaluation. Brain 1986a; 109: 279-292.

13. Sternberg DE, Jarvik ME. Memory functions in depression. Arch Gen Psychiatry 1976; 33: 219-224.

14. Stromgren LS. The influence of depression on memory. Acta Psychiat Scand 1977; 56: 109-128.

15. Mayeux R, Stem Y, Cote L, et al. Altered serotonin metabolism in depressed patients with Parkinson's disease. Cleveland: Neurol $1984 ; 34: 642-646$.

16. Santamaria J, Tolosa E, Valles A. Parkinson's disease with depression: a possible subgroup of idiopathic parkinsonism. Neurology 1986; 36: 1130-1133.

17. Fibiger HC, Philips AG. Reward, Motivation, Cognition: psychobiology of mesoelencephalic dopamine systems. In: Bloom FE, ed. The Nervous System IV, Handbook of Physiology. Am Physiol Soc, Bethesda, Md. 1986; 647-675.

18. Rogers D, Lees AJ, Trumble $M$, et al. Concept of bradyphrenia: a neuropsychiatric approach. Yahr MD, Bergmann KJ, eds. Raven Press, New York: Adv Neurol 1986; 45: 447-450.

19. Uhl GR, Hedreen J, Price D. Parkinson's disease: loss of neurons from the ventral tegmental area contralateral to therapeutic surgical lesions. Neurol 1985; 35: 1215-1218.
20. Marsden $C D$. The mysterious motor function of the basal ganglia: The Robert Wartenburg Lecture. New York: Neurol 1982; 32: 514-539.

21. Martilla R, Rinne U. Dementia in Parkinson's disease. Acta Neurol Scand 1976; 54: 431-441.

22. Pollock M, Hornabrook RW. The prevalence, natural history, and dementia of Parkinson's disease. Brain 1966; 89: 429-448.

23. Rajput AH, Offord K, Beard M, et al. Epidemiological survey of dementia in parkinsonism and control population. Hassler $G$, Christ J, eds. Raven Press, New York: Adv Neurol 1984; 40: 229-234.

24. Brown RG, Marsden CD. How common is dementia in Parkinson's disease? Lancet 1984; Dec. 1: 1262-1265.

25. Lees AJ. Parkinson's disease and dementia. Lancet 1985; Jan. 5: 43-44.

26. Kay DWK, Beamish P, Roth. Old age mental disorders in Newcastleon-Tyne. 1. A study of prevalence. Br J Psychiatry 1964; 110: 146-158.

27. Martin W, Loewenson R, Resch J, et al. Parkinson's disease. Clinical analysis of 100 patients. Neurol 1973; 23: 783-790.

28. Pirozzolo FJ, Hansch EC, Mortimer J, et al. Dementia in Parkinson's disease: a neuropsychological analysis. Brain and Cognition 1982; 1: 71-83.

29. Portin R, Rinne UK. Neuropsychological responses of parkinsonian patients to long-term Levodopa treatment. In: Rinne UK, Klinger M, Stamm G, eds. Parkinson's Disease - Current Progress, Problems, and Management. Elsevier/North Holland Biomedical Press 1980; 271-304.

30. Reitan R, Boll T. Intellectual and cognitive functions in Parkinson's disease. J Consult Clin Psychol 1971; 37: 364-369.

31. Hoehn MM, Yahr MD. Parkinsonism: onset, progression, and mortality. Minneapolis: Neurol 1967; 17: 427-442.

32. Taylor AE, Saint-Cyr JA, Lang AE. Dementia prevalence in Parkinson's disease. Lancet 1985; May 4: 1037.

33. Boller F, Mizutani T, Roessmann U, et al. Parkinson's disease, dementia, and Alzheimer's disease: clinicopathological correlations. Ann Neurol 1979; 7: 329-335.

34. Lieberman A, Dziarolowski M, Kupersmith $M$, et al. Dementia in Parkinson's disease. Ann Neurol 1979; 6, \#4: 355-359.

35. Hakim A, Mathieson G. Dementia in Parkinson's disease. Neurol 1979; 29: 1209-1214.

36. Price LP, Whitehouse PJ, Struble RG. Cellular pathology in Alzheimer's and Parkinson's diseases. TINS 1986; 9(1): 29-33.

37. Helig CW, Knopman DS, Mastri AR, Frey W. Dementia without Alzheimer pathology. Neurol 1985; 762-765.

38. Nakano I, Hirano A. Parkinson's disease: neuron loss in nucleus basilis without concomitant Alzheimer's disease. Ann Neurol 1984; $15 ; 415-418$

39. Candy JM, Perry RH, Perry EK, et al. Pathological changes in the nucleus of Meynert in Alzheimer's and Parkinson's diseases. J Neurol Sci 1983; 59: 277-289.

40. Jellinger K. Pathology of parkinsonism. In: Fahn S, ed. Recent Developments in Parkinson's Disease. Raven Press, New York 1986; 33-66.

41. Javoy-Agid F, Ruberg M, Hirsch E, et al. Recent progress in the neurochemistry of Parkinson's disease. In: Fahn S, ed. Recent Developments in Parkinson's disease. Raven Press, New York $1986 ; 67-83$.

42. Hornykiewicz O, Kish SJ. Neurobiochemical basis of dementia in Parkinson's disease. Can J Neurol Sci 1984; 11 (Suppl 1): 185-190.

43. McGeer E, Staines W, McGeer P. Neurotransmitters in the basal ganglia. Can J Neurol Sci 1984; 11 (Suppl): 89-99.

44. Epelbaum J, Ruberg M, Moyse E, et al. Somatostatin and dementia in Parkinson's disease. Br Res 1983; 278: 376-379.

45. Bowen F, Kamieny M, Burns M, et al. Parkinsonism: affects of Levodopa treatment on concept formation. Neurol 1976; 25: $701-704$.

46. Talland GA. Cognitive function in Parkinson's disease. J Nerv Ment Dis 1962; 135, 3: 196-205.

47. Tweedy J, Langer K, McDowell F. The effect of semantic relations on the memory deficit associated with Parkinson's disease. J Clin Neuropsychol 1982; 4: 235-247.

48. Taylor AE, Saint-Cyr JA, Lang AE. Frontal lobe dysfunction in Parkinson's disease - the cortical focus of neostriatal outflow. Brain 1986b; 109: 845-883. 
49. Flowers K, Pearce I, Pearce J. Recognition memory in Parkinson's disease. J Neurol Neurosurg Psychiatry 1984; 47: 1174-1181.

50. Proctor F, Ricklan M, Cooper I, et al. Judgement of visual and postural vertical by parkinsonian patients. Minneapolis: Neurol $1964 ; 14: 287-73$

51. Boller F, Passafiume D, O'Keefe N, et al. Visuospatial impairment in Parkinson's disease. Arch Neurol 1984; 41 : 485-490.

52. Bowen F, Hoehn M, Yahr. Parkinsonism: alterations in spatial orientation as determined by a route-walking test. Neuropsychologia 1972; 10: 355-361.

53. Bowen FP, Burns MM, Brady EM, et al. A note on the alterations of personal orientation in parkinsonism. Neuropsychologia 1976; 14: 425-429.

54. Botez MI, Barbeau A. Neuropsychological findings in Parkinson's disease: a comparison between various test during long-term Levodopa therapy. Int J Neurol 1975; 10, No. 1-4: 222-232.

55. Bowen FP. Behavioural alterations in patients with basal ganglia lesions. In: Yahr MD, ed. The Basal Ganglia. Raven Press 1976; 169-177.

56. Flowers $\mathrm{K}$. Lack of prediction in the motor behaviour of parkinsonism. Brain 1978; 101: 35-52.

57. Bloxham CA, Mindel TA, Frith CD. Initiation and execution of predictable and unpredictable movements in Parkinson's disease. Brain 1984; 107: 371-384.

58. Della Salla S, DiLorenzo G, Giordano A, Spinnler H. Is there a specific visuo-spatial impairment in parkinsonism? J Neurol, Neurosurg, Psychiatry 1986; 49: 1258-1265.

59. Brown RG, Marsden CD. Visuospatial function in Parkinson's disease. Brain 1986; 109: 987-1002.

60. Lees AJ, Smith E. Cognitive deficits in the early stages of Parkinson's disease. Brain 1983; 106: 257-270.

61. Talland GA, Schwab S. Performance with multiple sets in Parkinson's disease. Neuropsychologia $1964 ; 2: 45-53$.

62. Sternberg $R$, Tulving $E$. The measurement of subjective organization in free recall. Psychol Bull 1977; 84: 539-556.

63. Martone M, Butters N, Payner M, et al. Dissociations between skill learning and verbal recognition in amnesia and dementia. Arch Neurol 1984; 41: 965-970.

64. Delong MR, Georgopoulos AP, Crutcher MD. Cortico-basal ganglia relations and coding of motor performance. Exp Brain Res 1983; $7: 30-40$.

65. Alexander G, DeLong M, Strick P. Parallel organization of functioning segregated circuits linking basal ganglia and cortex. In: Cowan WM, ed. Annual Review of Neuroscience. Soc Neurosci, Washington 1986; 9: 357-381.

66. Kemp JM, Powell TPS. The cortico-striate projection in the monkey. Brain 1970; 93: 525-546.

67. Yeterian EH, Van Hoesen GW. Cortico-striate projections in the rhesus monkey: the organization of certain corticocaudate connections. Brain Res 1978; 139: 43-63.

68. Parent A, Bouchard C, Smith Y. The stiatopallidal and striatonigral projections: two distinct fiber systems in primate. Brain Res 1984; 303: 385-390.

69. Ilinsky LA, Jouandet ML, Goldman-Rakic PS. Organization of the nigrothalamocortical system in the rhesus monkey. J Comp Neurol 1985; 236: 315-330.

70. Kievet J, Kuypers HGJM. Organization of the thalamocortical connexions to the frontal lobe in the rhesus monkey. Exp Brain Res 1977; 29: 229-322.

71. Schell GR, Strick PL. The origin of thalamic inputs to the arcuate premotor and supplementary motor areas. J Neurosci 1984; 4: 539-560.

72. Van Hoesen GW, Yeterian EH, Lavizzo-Moury R. Widespread corticostriate projections from temporal cortex of the rhesus monkey. J Comp Neurol 1981; 199: 205-219.

73. Lieberman A. Parkinson's disease: a clinical review. Am J Med Sci 1974; 267: 66-80.

74. Penney JB, Young AB. Speculations on the functional anatomy of basal ganglia disorders. Ann Rev Neurosci 1983; 6: 73-94.
75. Goldman-Rakic. The frontal lobes: uncharted provinces of the brain. TINS 1984; 77.

76. Luria A. Higher cortical processes in man. Basic Books, New York 1980.

77. Milner B. Some cognitive effects of frontal lobe lesions in man. Philos Trans R Soc Lond [Biol] 1982; B298: 211-226.

78. Benton AL. Differential behavioural effects in frontal lobe disease. Neuropsychologia 1968; 6: 53-60.

79. Divac I. Neostriatum and functions of the prefrontal cortex. Acta Neurobiol Exp 1972; 32: 461-477.

80. Rosvold $H$. The frontal lobe system: cortical-subcortical interrelationships. Acta Neurobiol Exp 1972; 32: 439-460.

81. Rosenkilde CE, Bauer RH, Fuster JM. Single cell activity in ventral prefrontal cortex of behaving monkeys. Brain Res 1981;209: 375-394.

82. Thorpe SJ, Rolls ET, Maddison S. The orbital frontal cortex: activity in the behaving monkey. Exp Brain Res 1983; 49: 93-115.

83. Watanabe $M$. Prefrontal unit activity during delayed conditional discriminations in the monkey. Brain Res 1981; 225: 51-65.

84. Rolls ET, Thorpe SJ, Maddison SP. Responses of striatal neurons in the behaving monkey. 1 . Head of the caudate nucleus. Behav Brain Res 1983; 7: 179.210.

85. Evarts E, Kimura M, Wurtz R, et al. Behavioural correlates of activity in basal ganglia neurons. TINS 1984; 447-453.

86. Hikoska O, Wurtz RH. Modification of saccadic eye movements by GABA-related substances II. J Neurophysiol 1985; 53: 292-308.

87. Mishkin M, Malamut B, Bachevalier J. Memories and habits: two neural systems. In: Lynch G, McGaugh JL, Weinberger NM, eds. Neurobiology of Learning and Memory. Guilford Press, New York 1984; 65-77.

88. Newman RP, Weingartner $H$, Smallberg S, et al. Effortful and automatic memory: effects of dopamine. Neurol 1984; 805-807.

89. Brown RG, Marsden CD, Quinn N, et al. Alterations in cognitive performance and affect-arousal state during fluctuations in motor function in Parkinson's disease. J Neurol Neurosurg Psychiatry 1984; 47: 454-465.

90. Kish SJ, Rajput A, Gilbert J, et al. Elevated y-aminobutyric acid level in striatal but not extrastriatal brain regions in Parkinson's disease: correlation with striatal dopamine loss. Ann Neurol 1986; 20: 26-31.

91. Taylor AE, Saint-Cyr JA, Lang AE. Parkinson's disease: cognitive changes in relation to treatment reponse. Brain 1986; 110:35-51.

92. Saint-Cyr JA, Taylor AE, Lang AE. Procedural learning and neostriatal dysfunction in man. Brain, in press.

93. Hornykiewicz $\mathrm{O}$. Biochemical abnormalities in some extrastriatal neuronal systems in Parkinson's disease. In: Rinne VK, Klinger M, Stamm, eds. Parkinson's Disease - Current Progress, Problems and Management. Elsevier/North Holland Biomedical Press 1980; 109-119.

94. Javoy-Agid F, Ruberg M, Taquet $\mathrm{H}$, et al. In: Hassler RG, Christ JF, eds. Biochemical Neuropathology of Parkinson's disease. Raven Press, New York. Adv Neurol 1984; 40.

95. Scatton B, Rouquier L, Javoy-Agid F, et al. Dopamine deficiency in the cerebral cortex in Parkinson's disease. New York: Neurol 1982; 32: 1039-1040.

96. Scatton B, Javoy-Agid F, Rouquier L, et al. Reduction of cortical dopamine, noradrenaline, serotonin and their metabolites in Parkinson's disease. Brain Res 1983, 275: 321-328.

97. Perry RH, Tomlinson BE, Candy JM, et al. Cortical cholinergic deficit in mentally impaired parkinsonian patients. Lancet 1983; I: $789-790$.

98. Whitehouse PJ, Hedreen JC, White CL, et al. Basal forebrain neurons in the dementia of Parkinson's disease. Ann Neurol 1983; 13: 243-248.

99. Ruberg, M, Plosak A, Javoy-Agid F, et al. Muscarinic binding and choline acetlytransferase activity in parkinsonian subjects with reference to dementia. Brain Res 1982; 232: 129-139. 